
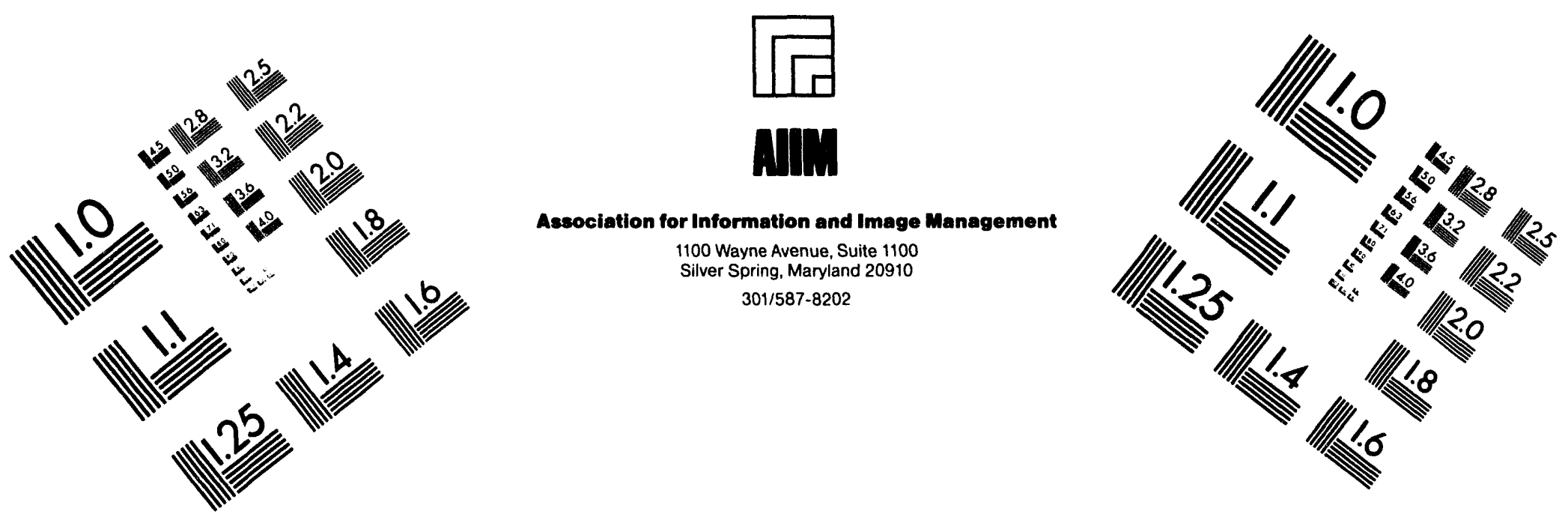

\title{
Centimeter
}

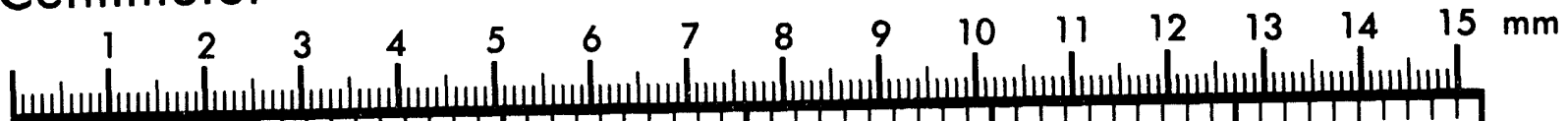
Im Inches
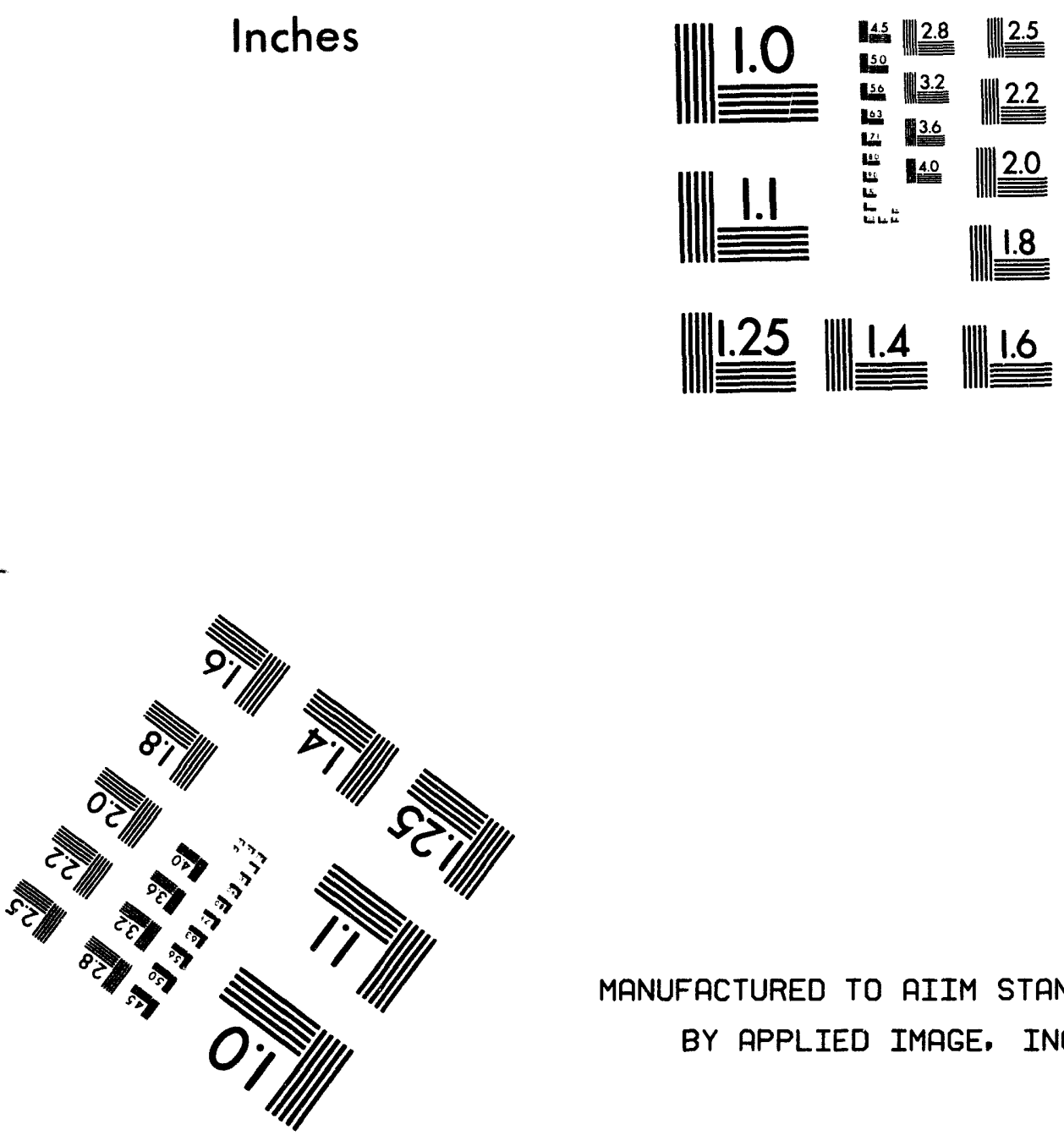

MANUFACTURED TO AIIM STANDARDS

$$
\text { BY APPLIED IMAGE, INC. }
$$

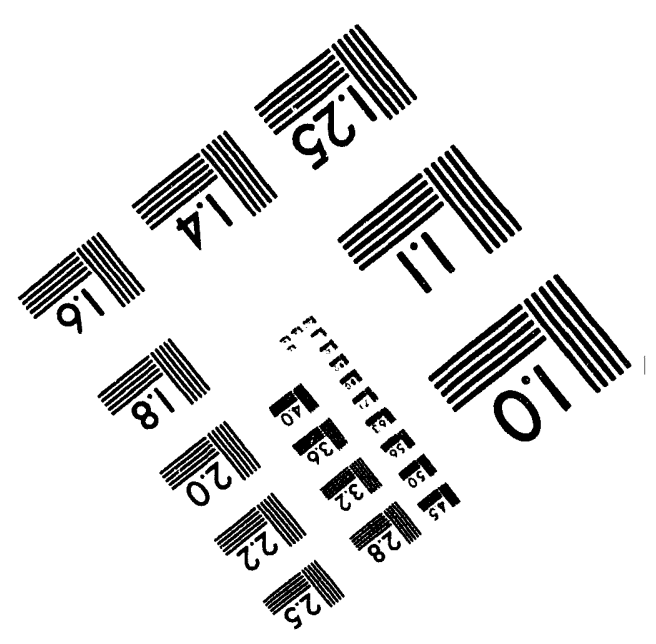



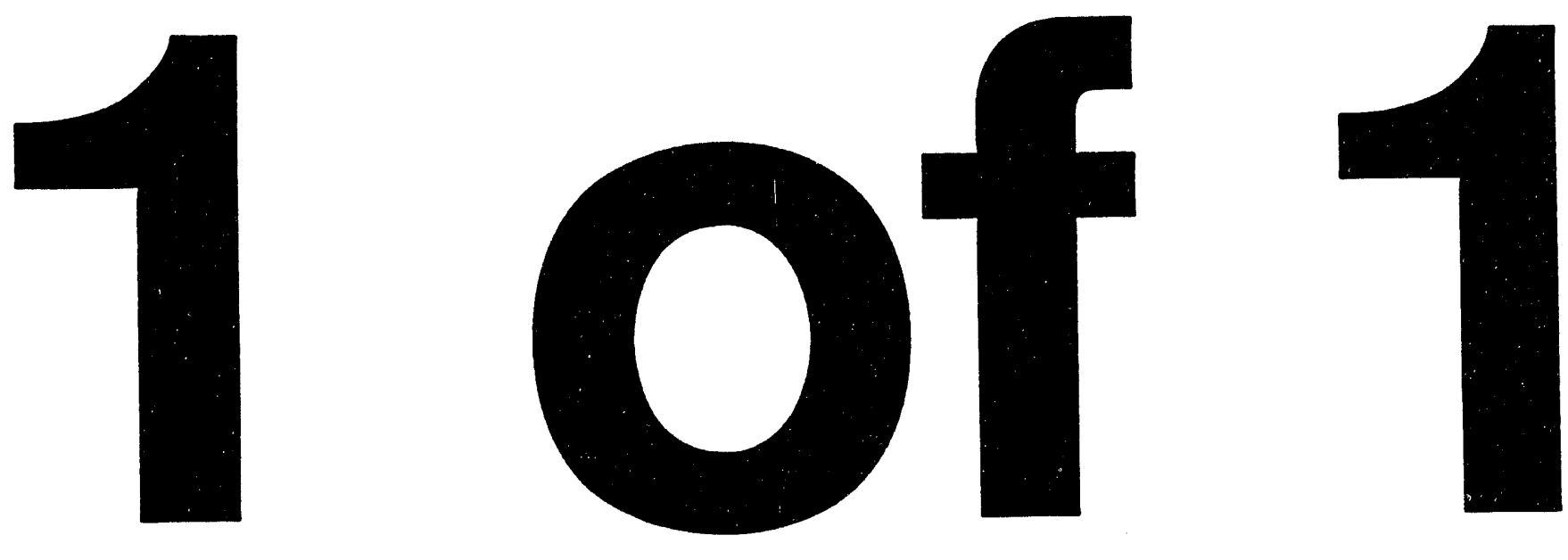


\section{MECHANISMS OF MECHANICAL FATIGUE IN CERAMICS}

ANNUAL TECHNICAL PROGRESS REPORT NO. 4

For the period August 15, 1992 through August 14, 1993

GRANT NO. DE-FG03-89ER45400

Prepared for:

U.S. Department of Energy

1333 Broadway

Oakland, CA 94605

Attn: James Solomon

Prepared by:

Brian Cox

JULY 1994

Rockwell International Science Center 
Science Center

SC71014.ATR

Table of Contents

Page

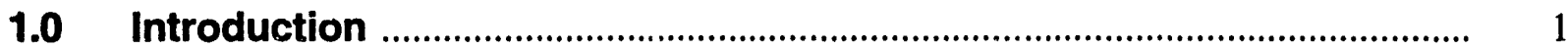

2.0 Theory of Rate Dependent Bridged Cracks ..................................................

3.0 High Temperature Crack Growth Experiments …......................................... 2

4.0 Collaborations and Supervision of Students ..............................................

5.0 References ….........................................................................................

6.0 Cumulative List of Papers Published Under This Contract ........................ 6

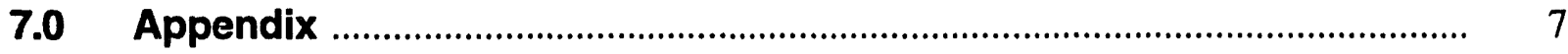

Life Prediction for Bridged/Fatigue Cracks ……………………………..... 8

A Self-consistent approximation for crack bridging by
elastic/perfectly plastic ligaments ................................................................ 50

DISCLAIMER

This report was prepared as an account of work sponsored by an agency of the United States Government. Neither the United States Government nor any agency thereof, nor any of their employees, makes any warranty, express or implied, or assumes any legal liability or responsibility for the accuracy, completeness, or usefulness of any information, apparatus, product, or process disclosed, or represents that its use would not infringe privately owned rights. Reference herein to any specific commercial product, process, or service by trade name, trademark, manufacturer, or otherwise does not necessarily constitute or imply its endorsement, recommendation, or favoring by the United States Government or any agency thereof. The views and opinions of authors expressed herein do not necessarily state or reflect those of the United States Government or any agency thercof. 


\section{Science Center}

SC71014.ATR

\subsection{Introduction}

This report covers work done in the second year of our three-year follow-on contract on "Mechanisms of Mechanical Fatigue in Ceramics." The theme of our work in this period continued to be the theory and measurement of rate-dependent bridging phenomena in fracture and fatigue. This covers both room temperature phenomena such as cycle-dependent attrition of crack bridging ligaments and high temperature phenomena such as viscosity and creep in bridging or cohesive zones. Our theoretical work focused on analytical solutions to rate dependent bridging problems. Our experimental work focused on developing high temperature in situ imaging methods. We obtained our first crack opening displacement measurements at elevated temperature in a graphite/ $\mathrm{SiC}$ composite.

\subsection{Theory of Rate Dependent Bridged Cracks}

In the prior year, we formulated and encoded numerical solutions for the integral equation governing a bridged crack when both crack advance and degradation of bridging contain rate dependent processes [1]. Simple constitutive laws were found for matrix cracks in fibrous composites and for patched cracks. Full numerical solutions were found and reported [1].

In the period of this report, we revisited this central problem, searching for analytical approximations. Solutions were sought based on the assumption of particular parametric forms for the crack opening profile: either an elliptical profile or one proposed earlier by Marissen [2] that is suitable for cracks approaching the limit of steady state cracking. Approximations were developed for the evolution of $\mathrm{K}_{\mathrm{tip}}$ as a function of time (or cycles) and crack length [3,4]. In some important regards, the approximations are very good. They provide a serviceable, simple method of reducing the fracture problem to either explicit solutions or, at worst, a transcendental equation in a single, scalar unknown. While the approximations have been tested so far only for rate dependent elastic bridging, we believe that they will prove equally viable for far more general bridging laws. They are currently being used, for example, in a collaboration with UC Santa Barbara to model cracks bridged by creeping fibers at high temperature.

We also pursued our interest in the problem of reducing bridged crack models to their simplest form, compressing micromechanical details into laws having physically correct form but containing the fewest possible parameters. A review of prior efforts to model fatigue crack data for matrix cracks in intermetallic alloys was undertaken, mainly as part of another program, but 


\section{Science Center}

SC71014.ATR

with attention to rate dependent problems conducted as part of this program. This exercise yielded an intuitive feeling for just how much detail about failure mechanisms can be inferred from fracture data taken alone. The answer is - rather little [5]. The need for the additional information available from in situ imaging data is highlighted.

Over the last two years, our code for solving bridged crack problems has grown considerably from our work under this contract. We are now sharing this valuable research tool with numerous colleagues - Bob McMeeking at UC Santa Barbara, Reiner Dauskardt at Stanford University (ex LBL), Victor Li at U. Michigan, Craig Carter at NIST, Chris Leung at MIT, and Francis Rose at ARL, Melbourne, Australia. Bob Wetherhold at SUNY Buffalo has written his own code following our original published paper. These collaborations are very important to optimizing our progress.

\subsection{High Temperature Crack Growth Experiments}

In the prior reporting period, we discussed observations made in an SEM of fatigue crack growth in graphite/SiC composites. In this period, we concluaied our analysis and reporting of these tests [6]. Estimates were made from bridged crack models of the temperature dependence of the critical stress for forming matrix cracks and of their opening displacements once formed. It was found that matrix cracks probably form more readily at high temperature and certainly have much larger opening displacements when they do. These trends suggest possible fatigue mechanisms for weak interface composites at high temperature that would be negligible at room temperature. A consistent account of experimental observations ensues [6]; along with a warning that while weak interfaces are beneficial at room temperature they can accelerate fatigue degradation at high temperatures.

We spent most of our experimental effort in learning to apply our high temperature in situ imaging techniques to ceramic composites at temperatures exceeding $1000^{\circ} \mathrm{C}$. This is a collaborative effort with Reiner Dauskardt of Lawrence Berkeley Laboratory (during the period of this report), who makes frequent visits to our laboratory (and still does, now from Stanford). We have assembled specialized crack growth control apparatus for brittle materials (Dauskardt), a thermally stable furnace and loading system, and optics for capturing images in situ. These images are then analyzed with our computer-based strain mapping system HASMAP. After considerable adjustments and design modifications, our first data were successfully taken for a graphite/SiC composite at $1000^{\circ} \mathrm{C}$. The analyzed images gave a very gratifying demonstration of 
Science Center

SC71014.ATR

the power of the method (Fig. 1). While damage was virtually invisible in individual micrographs, differential displacement fields deduced from pairs of micrographs clearly showed a crack-like band of damage emanating from a machined notch. This work has been reported as one aspect of a larger study conducted by Professor Dauskardt and Mike Mitchell under other funding [7].

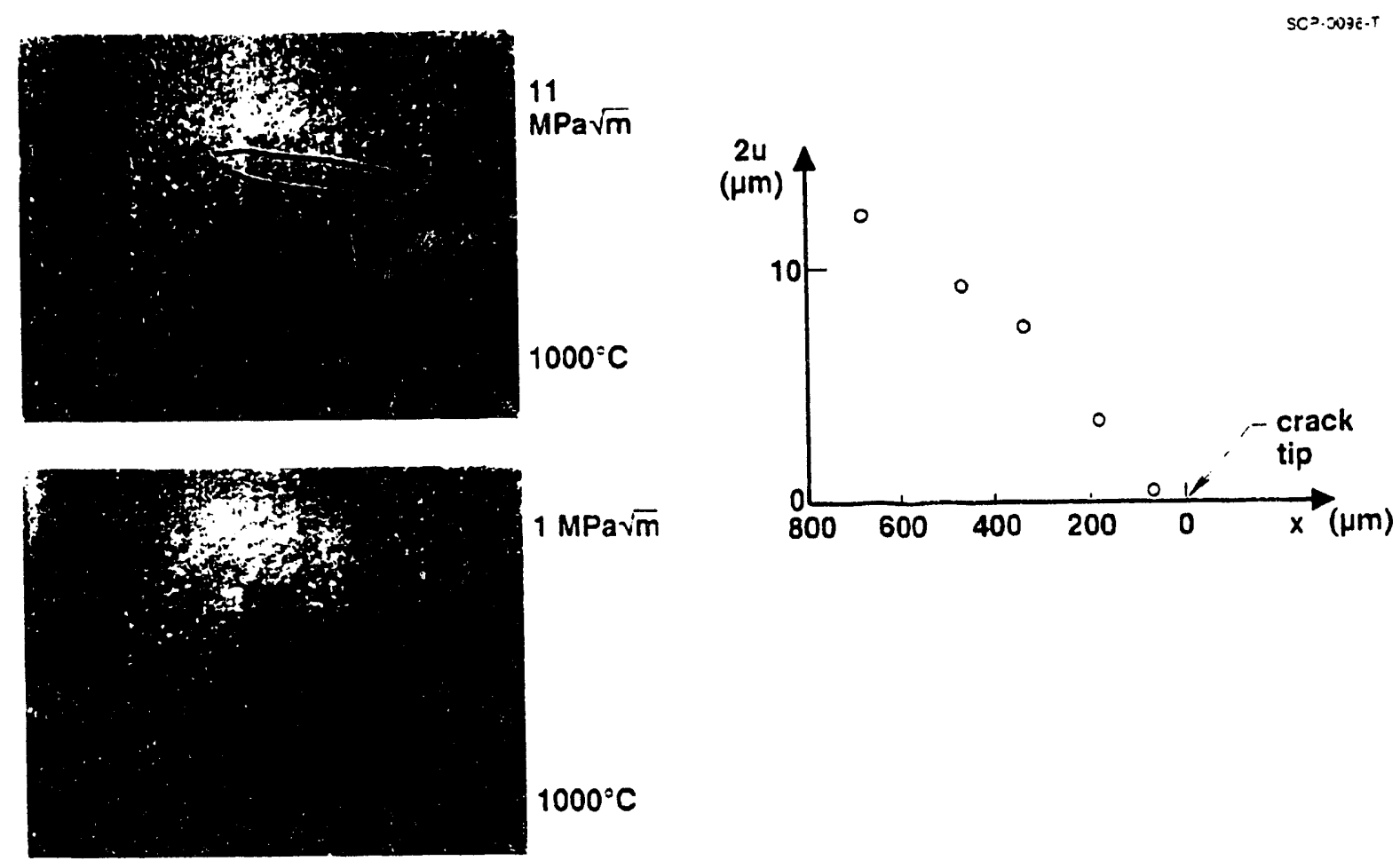

Fig. 1 Two optical images of a graphite/SiC composite taken in situ at $1000^{\circ} \mathrm{C}$, one at peak load and the other at low load; and the crack opening profile obtained from the images by stereoscopy. The "crack" in this case is actually a band of damage issuing from the notch. The crack growth experiment was conducted in our laboratory in collaboration with Dr. Reiner Dauskardt during one of his visits. Imaging and stereoscopy were performed on apparatus developed by Rockwell scientists (Dadkhah, Mitchell, and Morris).

Crack opening profiles were also measured by Fred Morris in our laboratory from photographs taken by Dr. Dauskardt of $\mathrm{Si}_{3} \mathrm{~N}_{4}$ in fatigue at room temperature. (Dr. Dauskardt's fatigue tests and in situ image gathering in this particular task were conducted entirely at LBL under his own DoE grant [8].) The profiles are shown in Fig. 2. These profiles are particularly significant in that they show premature closing of the crack profile behind the crack tip. We believe that this might be associated with a zone of microcracking, which exhibits a net dilatational strain in stereoscopy. The possibility that zones of microcracks might contribute 
Science Center

SC71014.ATR

significantly to toughness in nonequiaxed $\mathrm{Si}_{3} \mathrm{~N}_{4}$ is a minor revelation. Its ramifications for fatigue and high temperature behavior are now being researched.

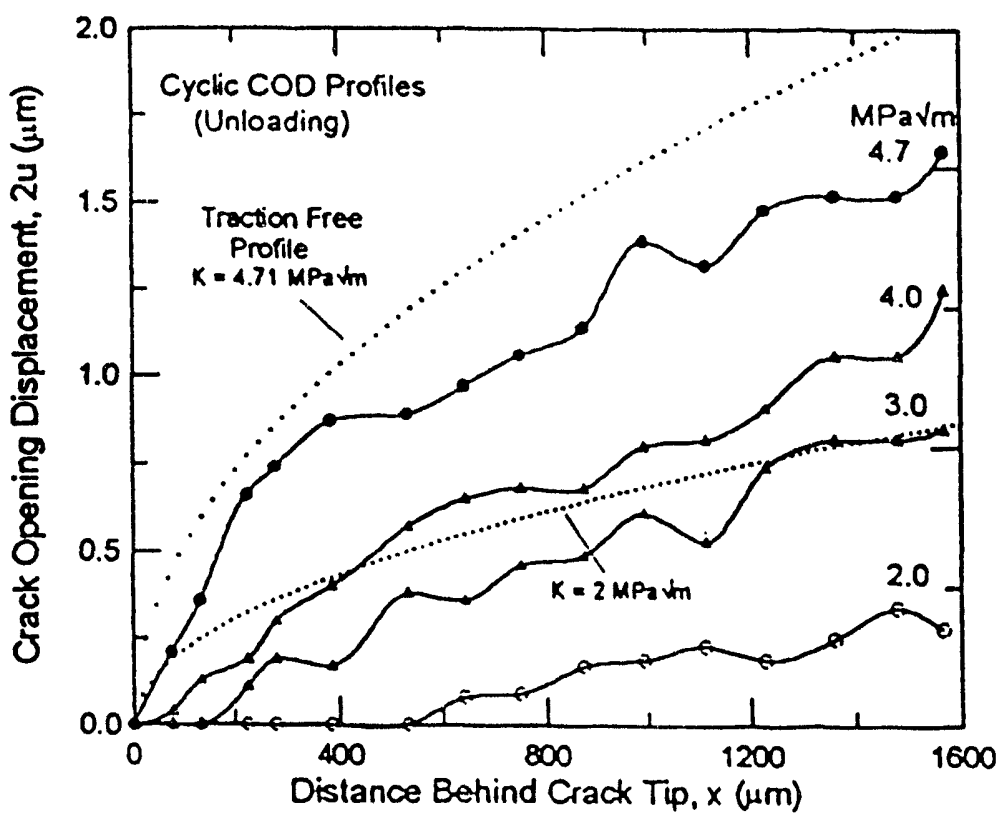

Fig. 2 Crack opening profiles for a fatigue crack in $\mathrm{Si}_{3} \mathrm{~N}_{4}$ measured during unloading. Comparison with the traction free profile (estimated by Dr. Dauskardt) at maximum load shows the strength of shielding from bridging grains. Significant premature closing at low loads is believed to originate in a dilatational zone of microcracks.

Other crack profiles measured at high temperature at Rockwell are still being analyzed.

\subsection{Collaborations and Supervision of Students}

We are enjoying a growing number of productive collaborations. Our oldest collaboration, that with Professor Reiner Dauskardt, previously of LBL and now of Stanford University, and Professor Rob Ritchie of LBL, continues very well. Reiner visits our laboratory two or three times a year to work on fracture experiments. We are now setting up a graduate student at Stanford to carry out bridged crack calculations for monolithic ceramics partly under the supervision of Brian Cox using the computer code developed here under this contract.

Dr. Francis Rose of ARL, Melbourne, continues to help us find analytical solutions to bridged crack problems. Personal meetings are limited by distance, but average one a year (DoE does not pay for the travel - the trips involved are mostly for other business). This has proven an adequate supplement to faxes and phone calls. 
Our relationship with UC Santa Barbara strengthens. Brian Cox now helps supervise Matt Begley, a Ph.D. candidate under Professor Bob McMeeking. Mr. Begley is running our bridged crack code to solve creep/fracture problems in fibrous ceramic composites.

Dr. Shanti Nair of Univ. Massachusetts visited us for several months in 1993 . He collaborated on high temperature crack growth experiments.

\subsection{References}

1.* B.N. Cox and L.R.F. Rose, "Time or Cycle Dependent Crack Bridging”, Mechanics of Materials, in press.

2. R. Marissen, "Fatigue Crack Growth in ARALL", Delft University of Technology Report LR 579, Delft, The Netherlands, 1988.

3.* B.N. Cox and L.R.F. Rose, "A Self-Consistent Approximation for Crack Bridging by Elastic/Perfectly Plastic Ligaments", to be submitted to Mechanics of Materials.

4.* B.N. Cox and L.R.F. Rose, "Quasi-Steady State Solutions for Time Dependent Bridged Cracks", in preparation.

5.* B.N. Cox, "Life Prediction for Bridged Fatigue Cracks", to be published in Proc. Symposium on Life Prediction Methodology for Titanium Matrix Composites, Hilton Head, South Carolina, March 1994, ed. W. S. Johnson, J. Larsen, and B. N. Cox, ASTM STP, 1994.

6.* W.L. Morris, B.N. Cox, M.R. James, R.V. Inman, and D.B. Marshall, "Fatigue Mechanisms in Graphite/SiC Composites at Room and High Temperature", J. Amer. Ceram. Soc., in press.

7. R.H. Dauskardt and M.R. Mitchell, "High Temperature Fatigue-Crack Growth Experiments in Ceramics and Ceramic-Matrix Composites", to be published in Proc. SEM Spring Conference, Baltimore, Maryland, June 6-8, 1994.

8. R.H. Dauskardt, "Cyclic Fatigue Crack Growth in $\mathrm{Si}_{3} \mathrm{~N}_{4}$ Ceramics", in Proc. Int. Conf. on Silicon Nitride, ed. M. J. Hoffman and G. Petzow, Academic Publ., 1993, in press. 
Science Center

SC71014.ATR

* Papers covering work done wholly or partly in this reporting period. All of the work in refs. 3, 4 , and $6,80 \%$ of the work in ref. 1 , and the work on rate dependent phenomena in ref. 5 was performed under this contract. In addition, the work on high temperature imaging in ref. 7 (a minor part of that work) was performed under this contract.

\subsection{Cumulative List of Papers Published Under This Contract}

\section{Papers}

Published work from prior years:

1. B.N. Cox and D.B. Marshall, "The Determination of Crack Bridging Forces", Int. J. Fracture 49, 159-76 (1991).

2. B.N. Cox and D.B. Marshall, "Stable and Unstable Solutions for Bridged Cracks in Various Specimens", Acta Met. Mater. 39, 579-89 (1991).

3. B.N. Cox, "Extrinsic Factors in the Mechanics of Bridged Cracks", Acta Met. Mater. 39, 1189-1201 (1991).

4. B.N. Cox and D.B. Marshall, "Crack Bridging in the Fatigue of Fibrous Composites", Fatigue Fract. Engng Mater. Struct. 14, 847-61 (1991).

5. B.N. Cox and C.S. Lo, "Load Ratio, Notch, and Scale Effects for Bridged Cracks in Fibrous Composites”, Acta Met. Mater. 40, 69-80 (1992).

6. B.N. Cox, "Fatigue and Fracture of Brittle Fibrous Composites", invited paper in Fatigue of Advanced Materials, ed. R.O. Ritchie, B.N. Cox, and R.H. Dauskardt (MCE Publ., Birmingham, England, 1991).

7. R.H. Dauskardt, R.O. Ritchie, and B.N. Cox, "Fatigue of Advanced Materials. Part I", Advanced Materials and Processes, Number 7 (1993) pp. 26-31.

8. R.H. Dauskardt, R.O. Ritchie, and B.N. Cox, "Fatigue of Advanced Materials. Part II", Advanced Materials and Processes, Number 8 (1993) pp. 30-35.

9. B.N. Cox, "Scaling Relations for Bridged Cracks", Mechanics of Materials 15, 87-98 (1993). 


\section{Science Center}

SC71014.ATR

10. B.N. Cox and D.B. Marshall, "Concepts for Bridged Cracks in Fracture and Fatigue", Overview No. 111, Acta Metall. Mater. 42, 341-63 (1994).

Published work from the year covered by this report (five further papers):

Refs. 1 and 3-6 from the list of references in Section 5.0

\section{Edited book}

Fatigue of Advanced Materials, ed. R.O. Ritchie, R. H. Dauskardt, and B. N. Cox, Proc. Engng Foundation Int. Conf., Santa Barbara, January 1991 (MCE Publ., Birmingham, UK, 1991).

\subsection{Appendix}

Preprints of refs. 3 and 5 from the References of Section 5.0. References 1 and 6 were included in last year's report in draft form and were not heavily modified and are therefore omitted here; reference 4 remains in a form that can be admired only by its authors.

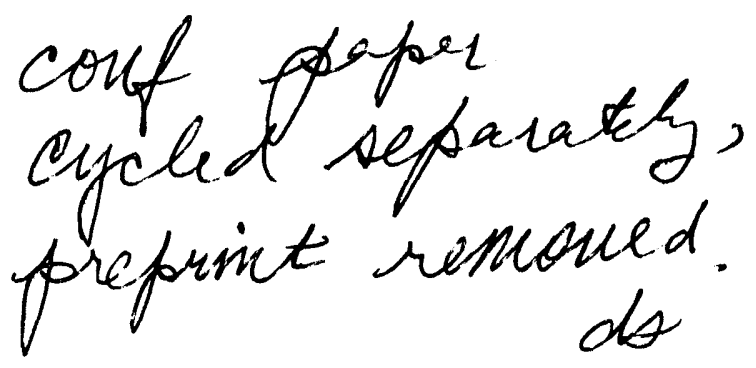



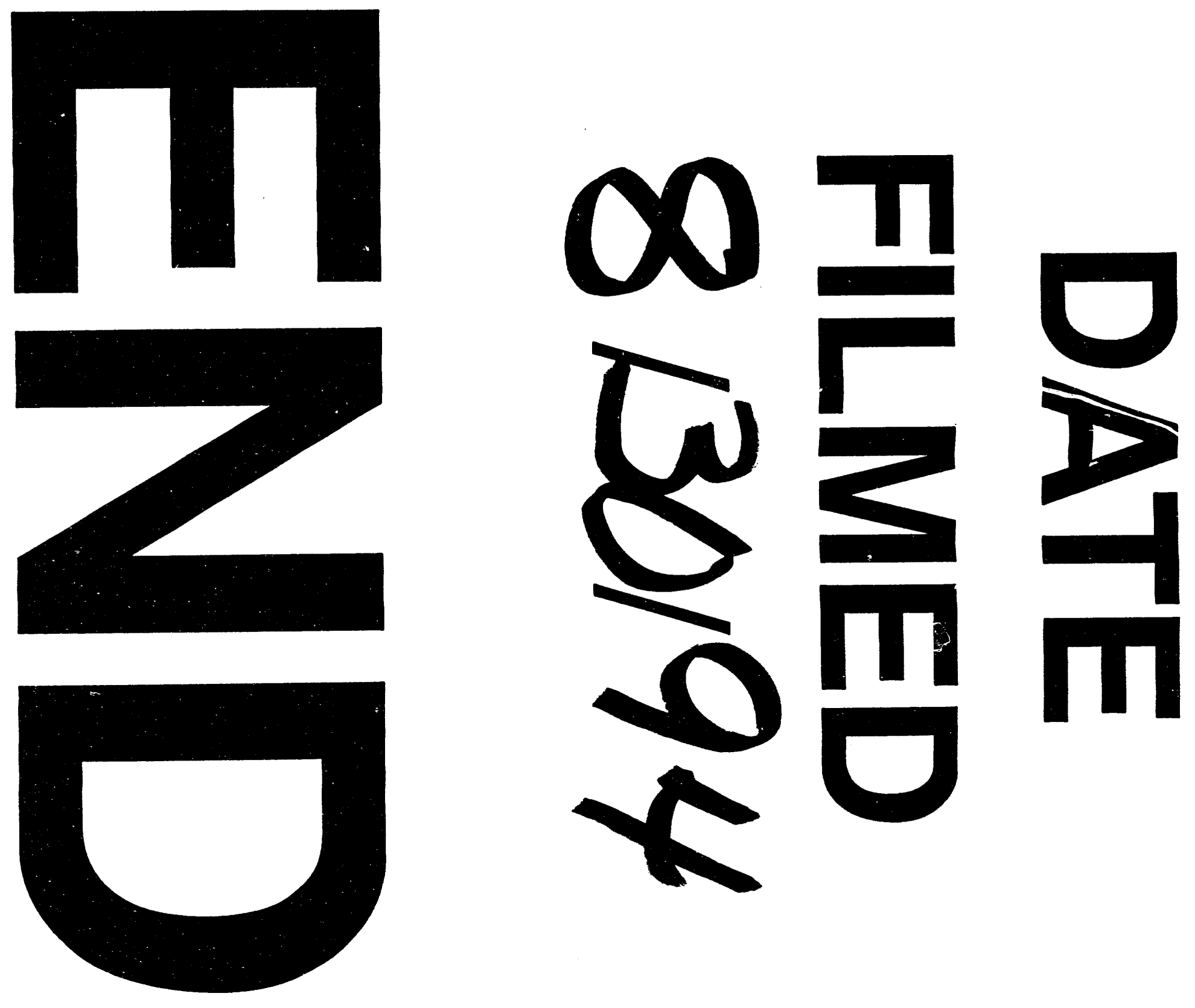
